\title{
Role of Surveying During Reconditioning of Monuments
}

\author{
András Veöreös ${ }^{1}$ \\ ${ }^{1}$ Györ-Moson-Sopron Megyei Kormányhivatal Győri Járási \\ Hivatal Építésügyi és Örökségvédelmi Osztály, Győr \\ Széchenyi István University, Department of History of \\ Architecture and Urban Planning and design Győr \\ andras.veoreos@gmail.com
}

\begin{abstract}
Ernö Foerk's most well-known work in architectural circles is certainly the volume published in the reprint edition, which collects the material of the building surveys conducted by the students of the Hungarian Royal Public Higher Architectural Industrial School between 1912-1942. The introduction to each volume shows that he considered to document the buildings as the main task of the surveys - besides their role in education - and thus to serve the Hungarian culture. Architectural surveying is still one of the most important starting points for monument reconditioning. Ideally, the process of monument reconditioning consists of the following steps: Scientific Research - Pre-planning Technical Studies - Compilation of a Planning Program and Planning - Professional Authority Control (getting of building permission) - Building Construction Work and (Fine Art) Restoration - Maintenance. This paper presents the essential role of surveying in this process.
\end{abstract}

Keywords: monument surveying, architectural surveying, true-to-form surveying

\section{ARCHITECTURAL SURVEYING}

In 1912, Ernő Foerk designated the service of Hungarian culture as the goal of the survey [1], but later also formulated the documentary and scientific significance of the work.

Researchers probably do not need to emphasize the importance of the role of architectural surveying in the process of reconditioning of monuments. However, fifteen years of first-line monumental supervisor experience shows that in everyday practice, a significant number of designers do not recognize the importance of this work, its potential, and do not produce documentation of necessary depth.

In the absence of a precise survey plan, the whole process becomes much more difficult: research on the construction history of the building suffers damage, making it more difficult to compile an assets inventory of monuments; starting data necessary for planning the recovery of technical condition as missing; the monument supervisory authority cannot make professional and substantiated decisions, so the permitting process is long-lasting; ultimately insufficient plans are created even damaging the assets of monuments on the basis of which no professional construction work can be done, that is instead of preserving of the assets to be restored their damage or destruction may occur.

The architectural survey is the technical drawing documentation of the building's geometry, the examination of the building, in which we can get a lot of information about the building without any damage. 
The traditional survey is made in two stages: at site the general plan, all typical ground-plans, sections and facades of the building are drawn in form of free-hand technical drawings.

The scale of the manual is about 1:50 in order to all relevant details can be represented. In addition to the drawing elements the manual can contain a lot of other information in text, so it can be considered the primary source of the knowledge about the building. In the second stage, on the basis of the manuals, the scaled technical drawing documentation is drawn or processed in the form of a digital model in a studio.

For the traditional survey, the points of the building are defined in relation to each other, so there is no external reference point in this case. An exception is putting down of vertical dimensions, it is worth (in the case of building standing on a sloping ground it is essential) to set a horizontal plane with a level or tubular bubble-level and to measure the points of the building in a vertical point of view in relation to it.

Due to the manual nature of the work, accuracy of the survey is a few centimetres, which - in case of manual processing - remains within "line width", so it is usually sufficient for scientific documentation and further planning.

In case if the aim of surveying is primarily to research with scholarly character, it is worth to make a true-to-form survey. In this case each point can be measured to a network (points, axes) independent of the building and the geometry of the building can be put down with much more accuracy.

In everyday practice true-to-form survey is made rarely, though it is specified by the current regulation [2]. (The contradiction probably arises from the difference in the use of the concepts by the legislator and the profession.)

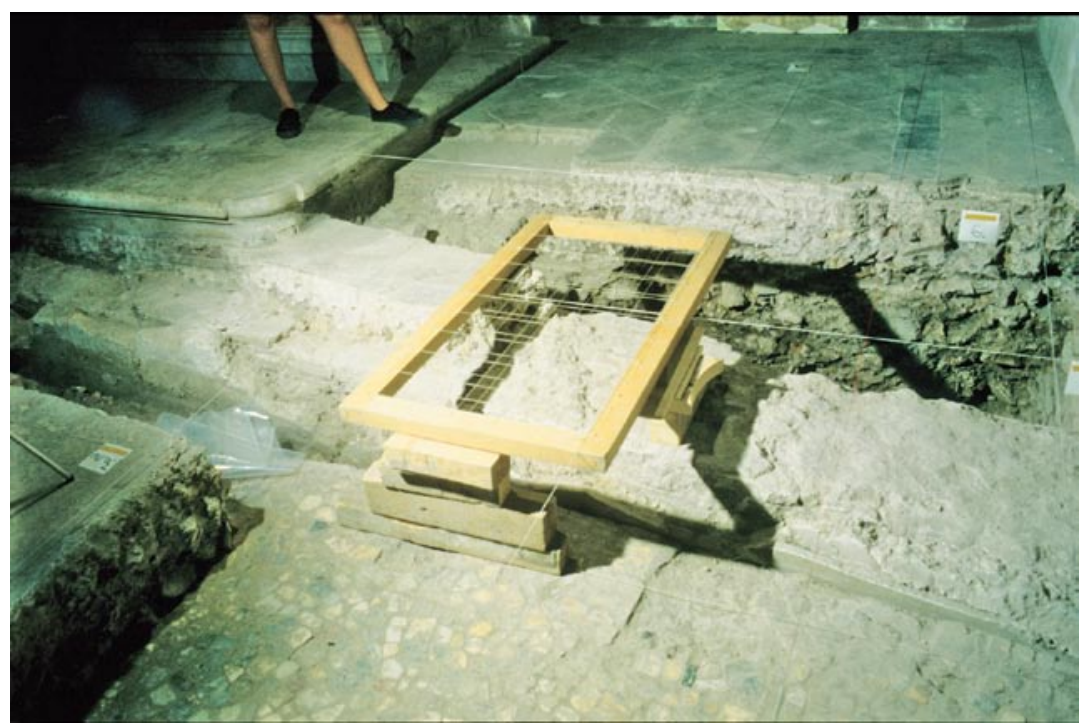

Figure 1. Tools of true-to-form survey: a cord-net independent of the building and a skeleton frame of square grade

Due to its high accuracy, a modern, digital model based on a bivariate point distribution can be considered a true-to-form survey, which is made prior to major restorations by architectural studios using modern technology and digital models during planning.

Application of the Building Information Model - BIM - for new buildings can be considered common. In addition to the geometry of the building, information on architectural, structural, static and mechanical details can be displayed on the model. In the case of monumental restoration, these can be supplemented with data from the historical research and survey of technical condition. 


\section{ROLE OF ARCHITECTURAL SURVEYING IN THE PROCESS OF MONUMENTAL RECONDITIONING}

Ideally, the process of monumental reconditioning consists of the following steps:

1. Scientific research;

2. Technical examinations prior to planning;

3. Setting up a planning program, planning;

4. Professional Authority Control (getting of building permission);

5. Construction work;

6. (Fine art) restoration;

7. Maintenance.

In the following, we are examining what tasks are for each survey.

\section{Scientific research}

The aim of the research is to get the history of the building known, to take the values of the monument into account and to establish the preservation of the values

The on-the-spot investigation examines the building itself, reveals the relative building order of the parts of the building, and enters the building parts with value of architecture and history of architecture. The on-the-spot research can be supplemented by non-on-the-spot research, i.e. by research in library, record office, archives of plans, files, photos by means of which the history of building can be attached to dates, the history can be made more accurate and known in details as well.

The role of the architectural survey in building historical research is extremely important in several respects.

During setting up a surveying plan a thorough, detailed observation of the building is necessary, since the survey technician is contacted twice with every small detail of the building when drawing and measuring.

The construction anomalies (fracture, wall thickness change, slotted openings, etc.) can get known during the field work or can be seen on the prepared survey plan, so the drawing documentation itself already contains information about the history of construction and identifies the necessary points of destructive research. For the proper documentation, the locations of planned wall examination can be indicated in the survey plan.

Mostly, the survey plan serves as a basis for representing information about the construction history, for making periodizing drawings or conceptual reconstructions showing the building in different states.

In addition, the survey plan provides an opportunity to visualize and identify objects in the monument assets inventory - to display additional information directly in case of a digital model.

It is important to note that the survey plan represents a building often changed over time at a given point in time, so it is also one of the most effective tools for documenting the momentary state. The drawn documentations recorded in several points of time can show the development history of the building. 


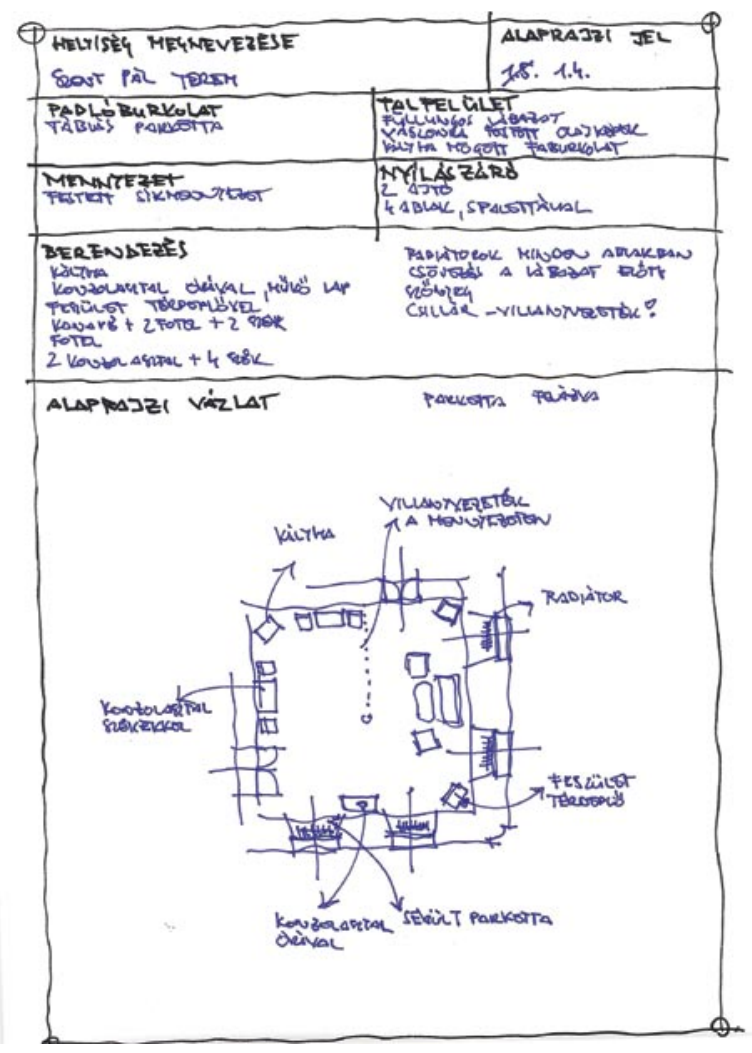

Figure 2. Representation of assets inventory on the survey plan (Szombathely)

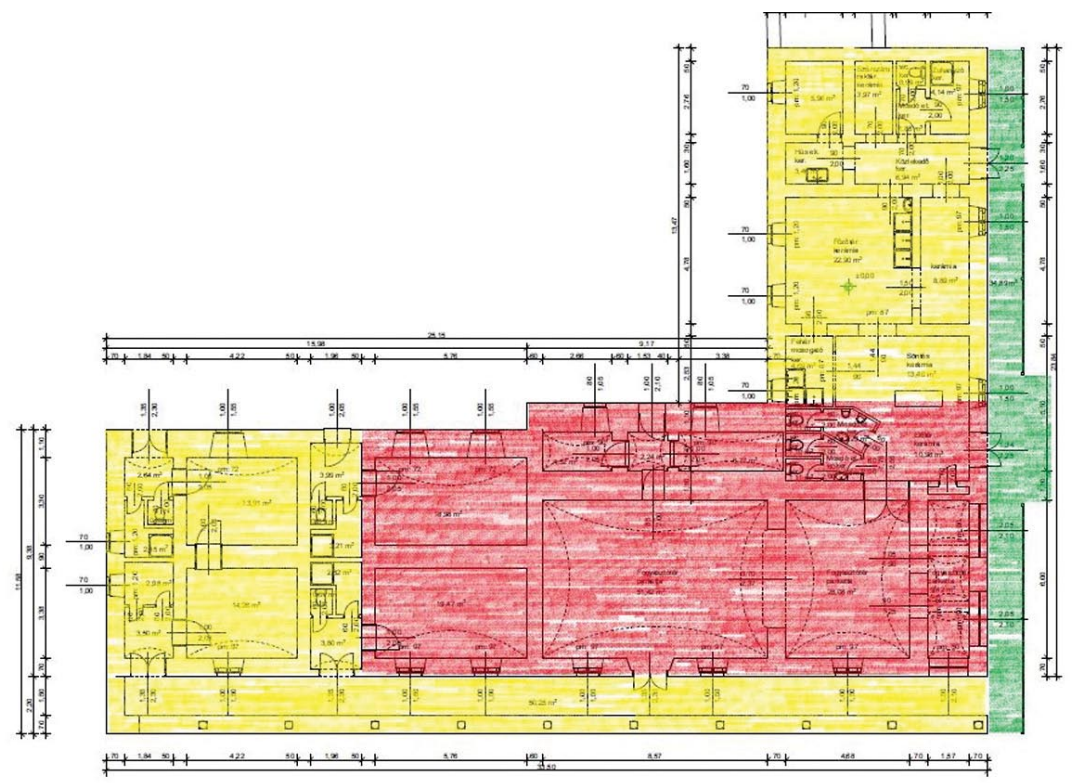

Figure 3. Periodizing ground-plan (Szigliget) 
In case of using a true-to-form surveying method the surveying method itself can helt the researcher in discovering historical findings, since by means of the detailed surveying documentation some information of construction history which are not visible in real may get visible. [3]

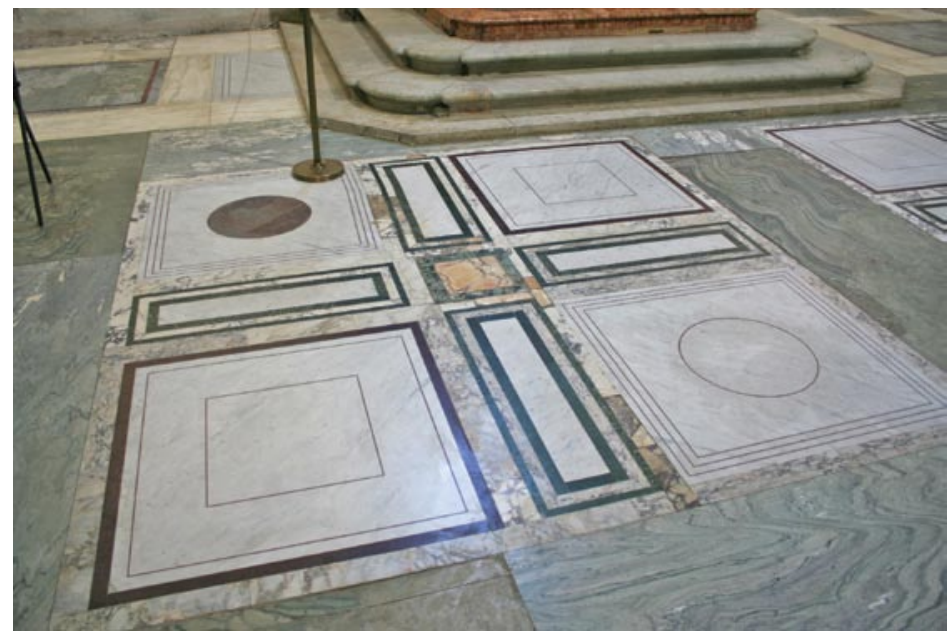

Figure 4. Early Christian floor reconstructed by means of the results of true-to-form survey on the Santo Rotondo Church in Rome

\section{Technical examinations}

The well-founded technical plan can be made on the basis of the results of detailed examinations. The (diagnostic) tests on the condition of a monument can include static, building construction, building physics and wood conservation examinations.

The structural survey can be performed by visual inspection, local instrumental testing or laboratory analysis of the sampling. The survey plan is the most suitable for displaying damage and defects in individual building elements. Information displayed in drawings naturally can be supplemented with text data as well.

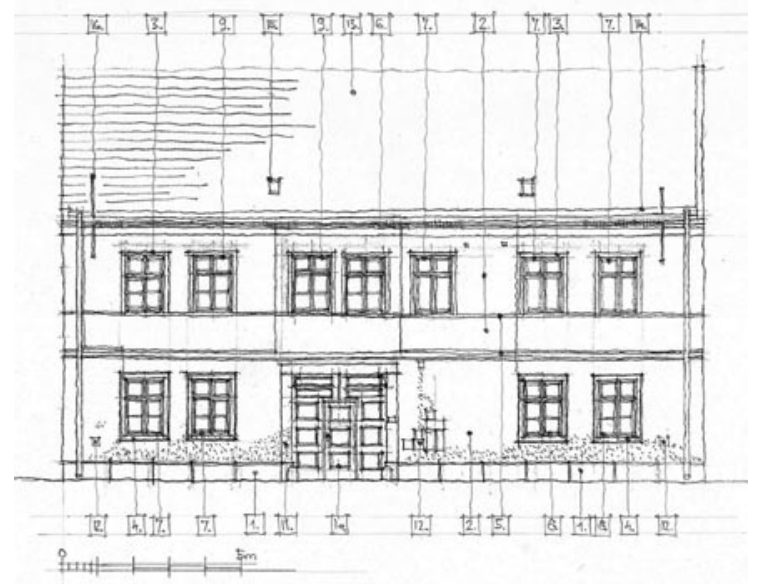

Figure 5. Condition recording façade drawing indicating defects (Sopron, Móricz Zsigmond Street) 
In addition, the survey plan can record the results of the building physics examinations such as data regarding to the moisture content of the walls or the state of wooden elements the roof structure.

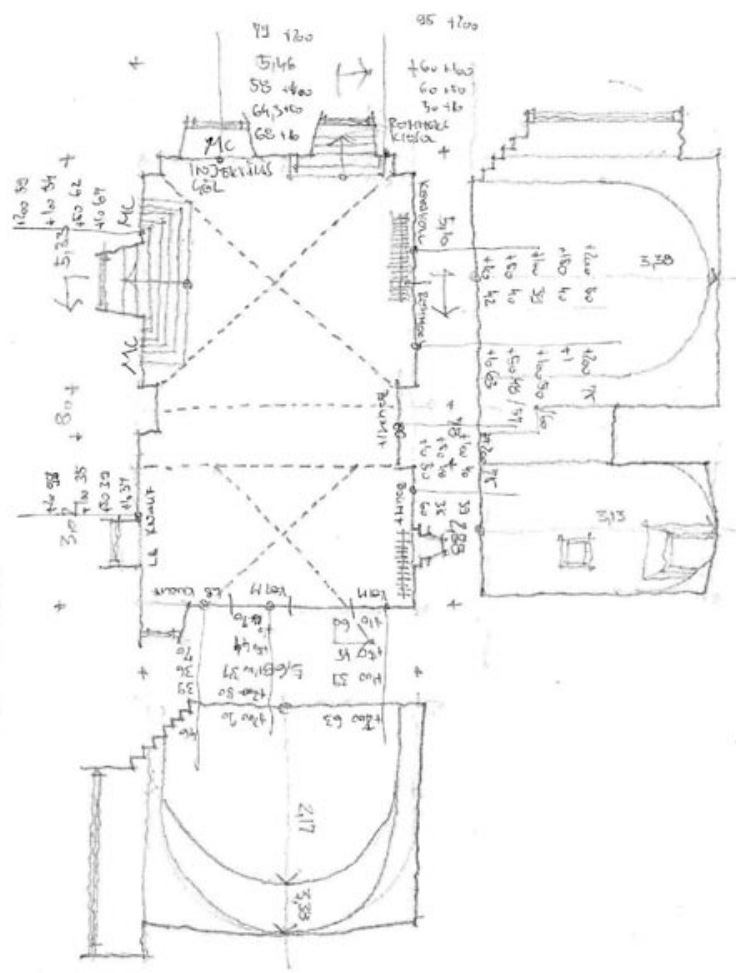

Figure 6. Representation of control measurement data for wall surface moisture content by marking the height of measurement points above floor level in a survey plan for a restored cellar room (Sopron, Kolostor Street)

\section{Planning program, planning}

The planning program formulates the objectives to be achieved for the renovation of the building in text. The planning program is drawn up on the basis of the results of research and preliminary examinations, taking into account the demands of the builder by the designer and the builder.

The technical project documentation is prepared on the basis of the planning program. The plan makes concrete proposals for solving technical problems. On the basis of the plan the calculation of the estimated costs can be stated. The planning documentation for the renovation of the building is made in several stages on an increasing scale and with increasing information content: concept plan, sketch design, permitting plan, plan for quotation request, building drawing. The basis of the plans is, of course, in every case the survey plan.

Surveying a building is the best method to get it known. In case if the designer personally participates in the survey work getting acquainted with the building, he can also take into evaluate the technical problems, so the part of the design program for the technical restoration can be prepared ,in mind' during the on-the-spot survey.

Naturally, the functional design of the building to be restored requires knowledge of the existing floor plan system of the building, the shape and dimensions of the individual rooms, so this part of planning is based on the survey documentation as well. 


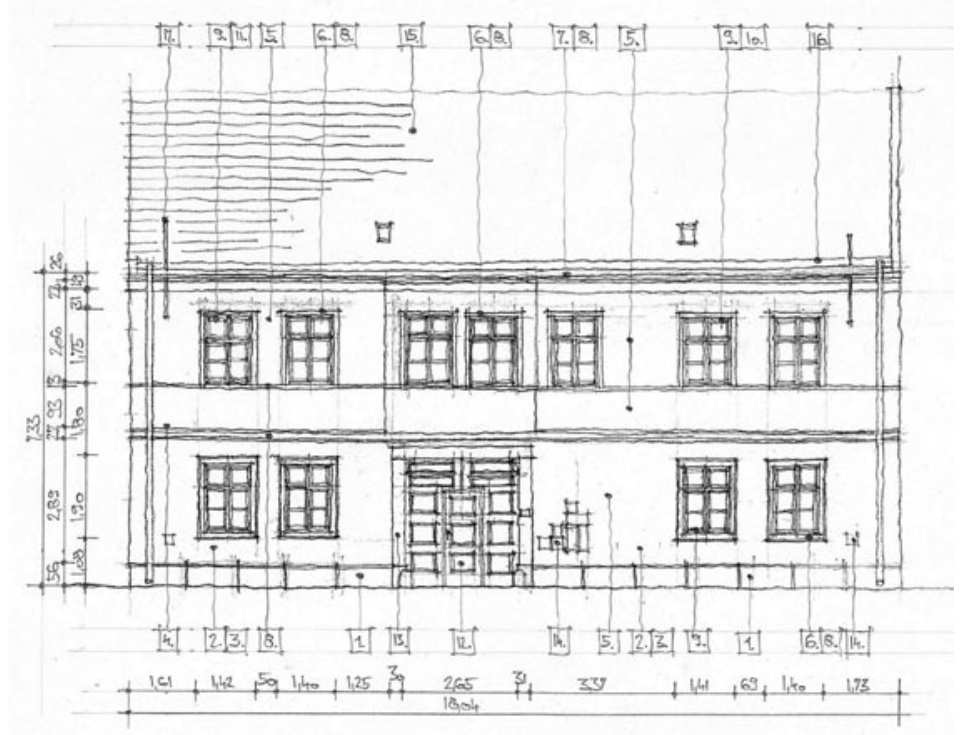

Figure 7. Façade drawing indicating the planned operations (Sopron, Móricz Zsigmond Street)

\section{Professional authority control (getting of building permission)}

The control of expertise of the plan is the permitting procedure during which the authority keeps in mind the properties of the building, preservation of its values and the professional interests of the builder.

On a monument building, any intervention can be carried out only after the professional control of the heritage protection authority. Depending on the nature of the operation, this can be a building permitting, heritage protection or heritage protection notification procedure. During the procedure, the authority compares the documentation presenting the existing state of the building with the plans of the planned state, based on the on-the-spot inspection or the knowledge of the building.

On the basis of the design documentation it can be clearly decided what impacts will be caused on the monument values by the different operations. The authority makes the decision taking them into account, in accordance with the relevant legal requirements.

\section{Construction work}

Construction work is an important stage in monument restoration. Basis of this work is the building drawing documentation which is logically based on the survey plan

In addition to the usual workpieces the building drawing documentation can include the way to protect the elements to be restored at site and to be restored later and the technical solutions for the renovation of individual building elements.

In case of renovation of monument buildings even after the most careful planning there may be cases when modifications have to be made during construction. The building drawings often include modifications subsequently put down on at site, so these pages become important elements of building documentation. 


\section{Restoration}

The term "restoration" refers to an artistic activity performed on the entire monument or on some of its elements with the aim of repairing damaged parts according to technical or aesthetic guidelines.

The restoration process has to be planned in advance, based on the damage map which can be represented in detailed survey drawings of the building (part). In addition, the visual and textual presentation of the planned operations as well as the documentation of the performed operation can be recorded on the survey drawings.

The drawings in this case require a high degree of precision and fullness of details, typically in a larger scale than usual $(\mathrm{M}=1: 20, \mathrm{M}=1: 10)$; often with the richness of details of the true-to-form survey.
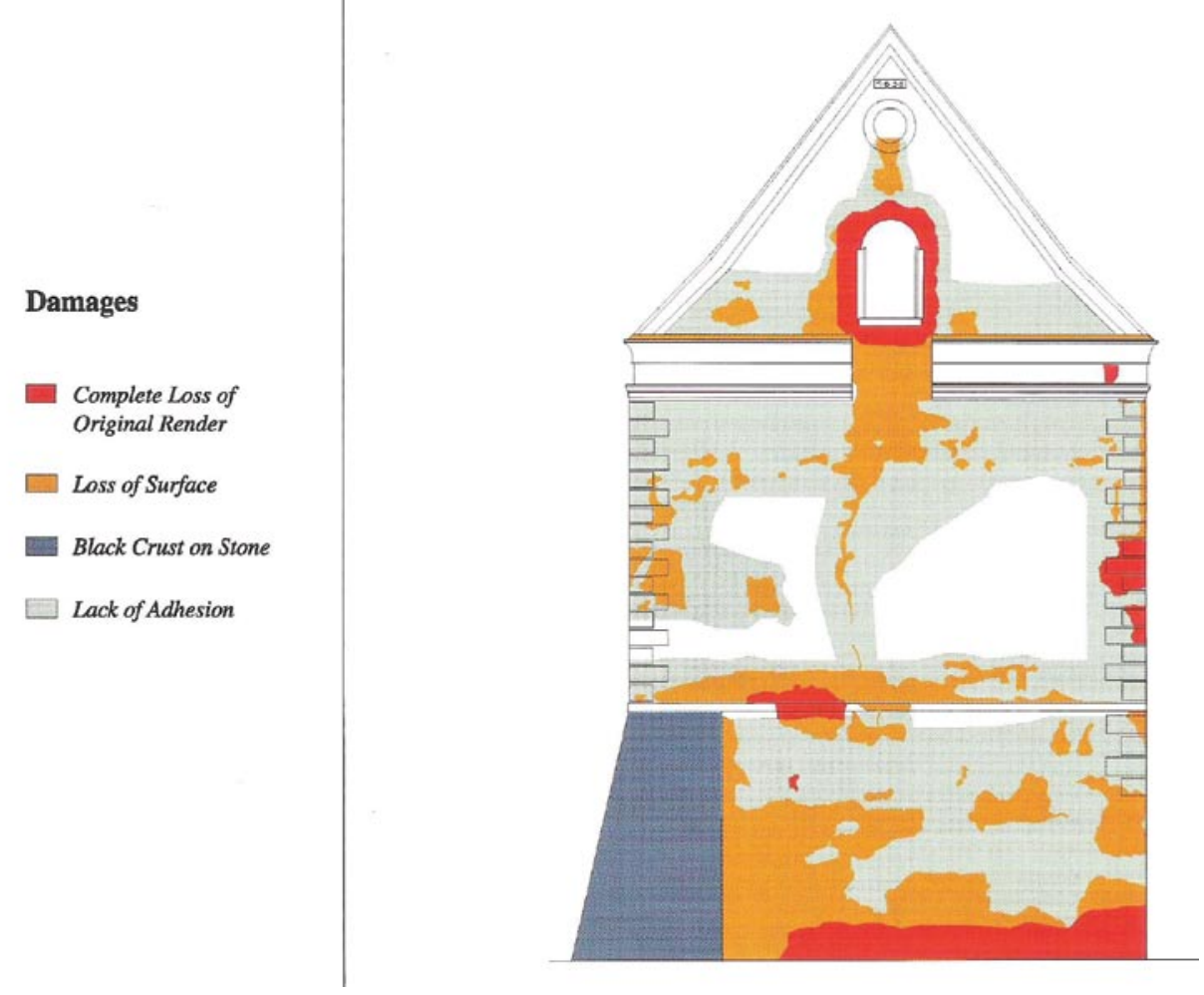

Figure 8. Display of a damage map (Kartause Mauerbach) [4]

\section{Maintenance}

Monument restoration work does not end with renovation, old buildings require permanent care and maintenance.

Documentation process of the maintenance operation is important for monitoring of the technical condition and monumental values of the building, this purpos is served by the service book specified also by the relevant regulation.

The most effective documentation method of the performed operations, repairs is to put them down on the technical plan documentation, i.e. the survey plan of the relevant building. 


\section{SUMMARY}

Summarizing the above it can be stated that the architectural survey made during the monument restorations

- is a part of the historical research on one hand, it is a great help in getting the buildinghistory of the building known;

- has an extremely big role in becoming acquainted with the building with the technical point of view, measuring the defects and so it is the base of the planning program of the technical restoration, on the other hand;

- thirdly, the geometry of the building is recorded during the survey, so the survey plan is also the basis for the design process;

- quarterly documents the current condition of the building, records the building historical information and the assets inventory of the building.

During the cognitive process and analytical work related to a precise survey with the architect's personal involvement, the planning program of the renovation is largely get developed, so no professional restoration can be imagined without surveying.

This article is made with the support of the EFOP-3.6.1-16-2016-00017 projekt: Internationalization, initiatives to establish a new source of researchers and graduates, and development of knowledge and technological transfer as instruments of intelligent specializations at Szechenyi University.

\section{REFERENCES}

[1] Széchenyi Holiday Records 1912-1942. Reprint Edition. Terc Publisher. Budapest.

[2] 68/2018 on Rules for the Protection of Cultural Heritage (IV. 9.) Government Decree Annex 12 Part II. A dot.

[3] Surveying of the Santo Stefan Church in Rome was finished in 2006. The surveying work was directed by architect Storz and archaeologist Brandenburg. The pattern of the early Christian floor, which has now been destroyed, has been managed to be conceived and reconstructed on the basis of the true-to-form survey of the remaining mortar.

[4] Decorated Renders around 1900 in Europe. Bundesdenkmalamt Arbeitshefte zur Baudenkmalpflege Kartause Mauerbach. BDA. Wien. 1999. pp 156. 